\title{
Evaluating the Effect of Ramadan Fasting on Muslim Patients with Diabetes in relation to Use of Medication and Lifestyle Patterns: A Prospective Study
}

\author{
Melanie Yee Lee Siaw, ${ }^{1}$ Daniel Ek Kwang Chew, ${ }^{2}$ Rinkoo Dalan, ${ }^{2}$ \\ Shaikh Abdul Kader Kamaldeen Abdul Shakoor, ${ }^{2}$ Noorani Othman, ${ }^{2}$ Chor Hui Choo, ${ }^{3}$ \\ Nur Hidayah Shamsuri, ${ }^{1}$ Siti Nurhana Abdul Karim, ${ }^{3}$ \\ Sui Yung Chan, ${ }^{1}$ and Joyce Yu-Chia Lee ${ }^{1}$ \\ ${ }^{1}$ Department of Pharmacy, Faculty of Science, National University of Singapore, Block S4, 18 Science Drive 4, Singapore 117543 \\ ${ }^{2}$ Department of Endocrine and Diabetes, Tan Tock Seng Hospital, 11 Jalan Tan Tock Seng, Singapore 308433 \\ ${ }^{3}$ Department of Pharmacy, Tan Tock Seng Hospital, 11 Jalan Tan Tock Seng, Singapore 308433
}

Correspondence should be addressed to Joyce Yu-Chia Lee; phalycj@nus.edu.sg

Received 14 August 2014; Accepted 22 October 2014; Published 11 November 2014

Academic Editor: Dario Iafusco

Copyright (C) 2014 Melanie Yee Lee Siaw et al. This is an open access article distributed under the Creative Commons Attribution License, which permits unrestricted use, distribution, and reproduction in any medium, provided the original work is properly cited.

Objectives. This study aimed to examine the effect of Ramadan fasting on HbAlc in Muslim patients with type 2 diabetes. The incidence of hypoglycemia and glycemic changes in relation to the adjustment of doses of antidiabetic agents, diet, and physical activity during Ramadan was also evaluated. Methods. This was a prospective study conducted in an outpatient endocrine clinic. A set of questionnaires was administered to Muslim patients with diabetes who fasted for $\geq 10$ days. Those who were hospitalized for diabetic ketoacidosis or severe hypoglycemia a month prior to Ramadan or were given short-term corticosteroid therapy were excluded. The patients' responses and clinical outcomes from the clinic database were collected before, during, and after Ramadan. Results. A total of 153 participants completed the study. The mean HbAlc improved from 8.9\% before Ramadan to $8.6 \%$ during Ramadan $(P<0.05)$. Although diet and physical activity did not contribute to changes in glycemia, a significant improvement in HbAlc was observed in patients who had adjustments made to their doses of antidiabetic agents during Ramadan $(P<0.001)$. In addition, their rate of hypoglycemia was minimal. Conclusions. Ramadan fasting appeared to improve glycemic control, especially in those whose doses of antidiabetic agents were adjusted during Ramadan.

\section{Introduction}

Ramadan is a holy month in the Islamic calendar during which Muslims all over the world observe a fast between dawn and sunset. During Ramadan, Muslims who are ill or have health conditions that may deteriorate upon fasting, including patients with diabetes, are exempt [1]. However, fasting during Ramadan is highly regarded as a form of religious practice, and thus many devoted Muslim patients insist on fasting despite being advised not to by their healthcare providers. It has been estimated that $40-50$ million individuals with diabetes fast during the month of Ramadan [2].

Ramadan fasting entails major changes in dietary patterns and frequency. These changes could potentially induce metabolic alterations in both healthy and diseased Muslims $[3,4]$. Despite taking fewer meals, this practice is usually compensated by ingesting large amounts of sugary food and drinks that are high in carbohydrates and fats, especially when breaking the fast [5]. The overall calorie consumption of individuals with type 2 diabetes has been reported to increase during Ramadan $[6,7]$. Moreover, the doses of antidiabetic 
agents are often adjusted at this time to reflect the change in lifestyle during Ramadan. One study showed that, among diabetic patients whose doses of oral hypoglycemic agents (OHA) were modified during Ramadan, 58\% had changed the timings of the administration of their medications [8].

During Ramadan, it has also been reported that physical activities, especially exercising, tend to decrease from a fear of feeling too weak [9]. Patients with diabetes have been advised by healthcare providers to avoid excessive physical activity during Ramadan, because the practice of fasting may increase the risk of hypoglycemia, especially a few hours before the sunset meal. However, one study reported that appropriate levels of physical activity during fasting did not interfere with tolerance to physical exercise [10].

Furthermore, it has also been postulated that the act of fasting may increase the risk of poor glycemic control, which raises questions about the safety of Ramadan fasting in patients with diabetes. During Ramadan fasting, the decrease in blood glucose levels triggers compensatory mechanisms in the body of healthy individuals which cause a reduction in insulin secretion or the breakdown of stored glycogen to prevent hypoglycemia [11]. However, in patients with diabetes, this regulation is compromised due to either a dysfunction of insulin secretion or sensitivity or occasionally both [12]. One epidemiological study reported that the risk of severe hypoglycemia increased sevenfold during the month of Ramadan in patients with diabetes [2]. However, another study reported that Ramadan fasting was safe and did not significantly increase the incidence of hypoglycemic events [13].

The primary objective of this prospective study was to evaluate the effect of fasting during Ramadan on the glycemic control of Muslim patients with type 2 diabetes by examining the changes in levels of HbAlc before, during, and after Ramadan. In addition, the incidence of hypoglycemia and changes in glycemic control in relation to the adjustment of doses of antidiabetic agents, diet, and physical activity during Ramadan were examined.

\section{Methods}

2.1. Study Design and Site. This was a prospective study conducted in an outpatient endocrine clinic located within a tertiary hospital in Singapore between June and November 2012; Ramadan took place from July 21 to August 18, 2012. In Singapore, Muslims account for $14.7 \%$ of the population [14], and, during Ramadan, Muslims fast for 30 days [15]. The study, which was approved by the Institutional Review Board, comprised of data collection from the institutional database and the administration of a set of questionnaires by trained interviewers. Eligible patients were screened and approached to determine their interest in participating in this study a month before Ramadan. Upon signing the consent form, a set of questionnaires was administered to study patients by interviewers before, during, and after Ramadan. Data on pertinent clinical outcomes were also collected at the three time periods.
2.2. Inclusion and Exclusion Criteria. All Muslim patients over 21 years of age with type 2 diabetes who fasted for at least 10 days [16] during the month of Ramadan were included in this study. The patients who reported having been hospitalized for diabetic ketoacidosis or severe hypoglycemia a month prior to Ramadan or those who received shortterm corticosteroid therapy were excluded from the study. In addition, the patients who were unable to comprehend the questionnaire were excluded from the study.

2.3. Questionnaire. The questionnaire used in this study was adapted from a 2011 prospective study after consent was obtained from the authors [8]. The questionnaire comprised a sociodemographic section, which included age, gender, level of education, employment status, body mass index, health status, and duration of diabetes, and a section on the types of antidiabetic agents used and dosing regimens, the patients' perception of their daily physical activities, and their dietary patterns. For the questions relating to diet and physical activity, changes in these parameters during Ramadan were self-reported by the patients based on a response of more, less, or unchanged.

Minor amendments were made to questions related to sociodemographics and diet to suit the local context. The questionnaire was translated into the Malay language commonly spoken by the Muslim population in Singapore. Questionnaires were administered to patients in their preferred language by the trained, bilingual interviewers and took approximately 30 minutes to complete.

Outcome measures, such as HbAlc, and responses to the questionnaire were collected before, during, and after Ramadan. HbAlc is a surrogate marker, commonly used in numerous studies related to Ramadan fasting, which reflects glycemic control in Muslim patients; it gives a more reliable reflection of the average plasma glucose concentration over 8-12 weeks [17]. In this study, the incidents of hypoglycemia were classified as minor or major. Minor hypoglycemia was defined as an event that can be self-managed by patients irrespective of the severity of the symptoms, while severe hypoglycemia was defined as an event that requires the assistance of a third party to effect treatment [18]. The study patients were also asked if they had experienced any symptoms of hypoglycemia during Ramadan fasting [8].

2.4. Statistical Analysis. The data are presented as means \pm standard deviations (SD) for continuous variables and as percentages for categorical variables. The outcome measure, $\mathrm{HbAlc}$, was analyzed between two time periods using a linear mixed model; this was followed by pairwise comparisons with Bonferroni adjustment. Diet and physical activities were compared with HbAlc as binary outcomes in logistic regression. All of the analyses were adjusted for age, gender, BMI, level of education, total comorbidities, duration of diabetes, and employment and health status. After multiplication by the number of repeated analyses where appropriate, a twotailed $P<0.05$ was considered to be significant. The computations were performed using SPSS for Windows, version 19.0 (SPSS Inc., Chicago, IL, USA). 
TABLE 1: Patient demographics and attributes.

\begin{tabular}{lc}
\hline Patient characteristics & All $(n=153)$ \\
\hline Gender & $57(37.3)$ \\
Male & $96(62.7)$ \\
Female & $56.7 \pm 9.1$ \\
Age (years) & $30.4 \pm 6.7$ \\
BMI (kg/m ${ }^{2}$ ) & \\
Education level & $11(7.2)$ \\
$\quad$ No formal education & $52(34.0)$ \\
1st to 6th grade & $81(52.9)$ \\
7 th to 12th grade & $9(5.9)$ \\
College/university & \\
Employment status & $63(41.2)$ \\
Employed & $90(58.8)$ \\
Unemployed & $26 \pm 5$ \\
Average number of fasting days & $13.2 \pm 9.1$ \\
Duration of diabetes (years) & $4 \pm 2$ \\
Comorbidities & \\
Antidiabetic medication & \\
No medication & $3(2)$ \\
OHA $^{\mathrm{b}}$ alone & $57(37.3)$ \\
Insulin alone & $21(13.7)$ \\
OHA $^{\mathrm{b}}$ and insulin & $72(47.1)$ \\
\hline
\end{tabular}

Data are presented as number (\%) or means \pm SD.

${ }^{a}$ The three most common comorbidities were hypertension, hyperlipidemia, and neuropathy.

${ }^{\mathrm{b}}$ Oral hypoglycemic agent.

\section{Results}

Of the 251 patients recruited, 98 (39\%) were excluded from the analysis due to incomplete responses. At the completion of the study, 153 patients with an average of 26 fasting days had been followed up throughout the entire study to give a response rate of $61 \%$. Their mean age was $56.7 \pm 9.1$ years and $62.7 \%$ of the participants were women $(n=96)$ (Table 1$)$. A large majority ( $n=81 ; 52.9 \%)$ of the study subjects had at least a 12th grade education. However, more than half of the participants were unemployed $(n=90 ; 58.8 \%)$. With regard to diabetes management, 150 (98\%) were taking antidiabetic agents of which $72(47.1 \%)$ were on a combination regimen of OHA and insulin. Metformin was the most commonly prescribed OHA ( $n=119 ; 92.2 \%)$, followed by sulfonylurea $(n=70 ; 54.3 \%)$ and dipeptidyl peptidase 4 inhibitors $(n=11$; $8.5 \%)$. The majority were given basal insulin concurrently with mealtime insulin $(n=61 ; 65.6 \%)$ while the remainder were either given basal insulin $(n=31 ; 33.3 \%)$ or mealtime insulin alone $(n=1 ; 1.1 \%)$ (Table 2$)$.

3.1. Effect on HbA1c. Mean HbAlc improved from $8.9 \pm$ $2.0 \%$ before Ramadan to $8.6 \pm 1.8 \%$ during Ramadan $(P<$ $0.05)$. However, this improvement was not sustained after Ramadan. An increase of $0.2 \%$ in mean HbAlc was observed between Ramadan and after Ramadan $(P>0.05)$ (Figure 1).

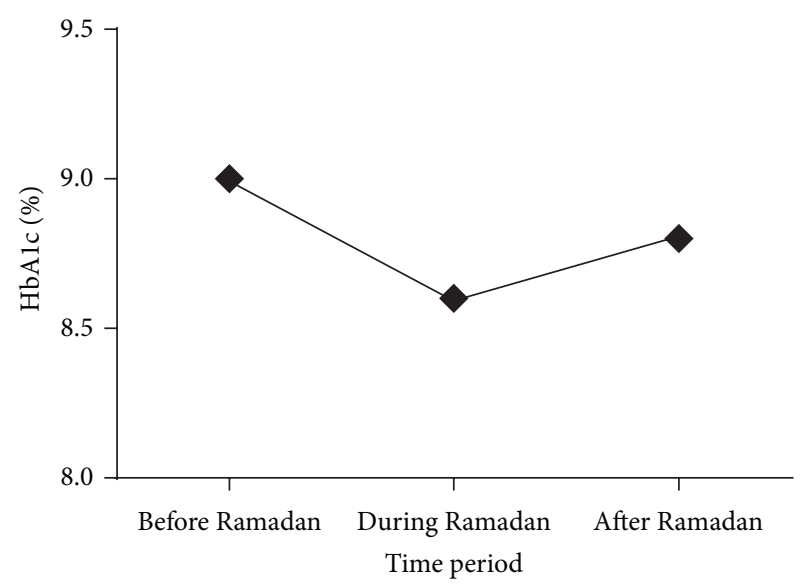

FIgURE 1: Trends of change in mean HbAlc.

3.2. Dose Adjustment in relation to Glucose Control. During Ramadan, the most common method of dose adjustment made by the OHA users was a reduction in total daily dose ( $n=55 ; 73.3 \%)$. The other methods of dose adjustment were cessation of OHA $(n=9 ; 12.0 \%)$, increased night-time dose alone $(n=5 ; 6.7 \%)$, increased total daily dose $(n=3$; $4.0 \%)$, and additional OHA $(n=3 ; 4.0 \%)$. In this study, the three most commonly adjusted OHAs were metformin, glipizide and its equivalents $[19,20]$, and sitagliptin with average dose reductions of $810.4 \pm 632.2 \mathrm{mg}, 4.5 \pm 6.9 \mathrm{mg}$, and $16.7 \pm 57.7 \mathrm{mg}$, respectively, during Ramadan. Among the insulin users, the total daily insulin dose was reduced by $39(60.9 \%)$ patients and stopped by five $(7.8 \%)$ patients. Of the remaining patients who adjusted their insulin therapy, two $(3.1 \%)$ took additional insulin, six $(9.4 \%)$ increased their total daily dose, and $12(18.8 \%)$ increased their night-time insulin dose alone. Overall, the average dose adjustments of insulin during Ramadan for mealtime and basal insulin were $-11.8 \pm 13.6$ units and $-8.1 \pm 10.4$ units, respectively.

An improvement in mean $\mathrm{HbAlc}$ from $9.2 \pm 1.9 \%$ before Ramadan to $8.7 \pm 1.6 \%$ during Ramadan was observed in patients who made dose adjustments during Ramadan $(n=$ 104; $P<0.001)$. In patients who did not make any dose adjustments during Ramadan, no significant improvement in HbAlc was observed $(n=49 ; P>0.05)$ (Figure 2$)$.

3.3. Diet and Physical Activity in relation to Glucose Control. During Ramadan, 99 (64.7\%) participants reported a reduction in dietary intake, $45(29.4 \%)$ reported an unchanged dietary intake, and nine (5.9\%) reported an increased dietary intake. With regard to physical activity, the majority ( $n=$ 96; 62.7\%) reported an unchanged level of activity while 49 (32\%) reported less activity and eight (5.2\%) increased their level of activity during Ramadan. These perceived patterns of diet and physical activity were, however, found to have no significant association with the improvements in mean HbAlc during Ramadan fasting $(P>0.05)$.

3.4. Incidents of Hypoglycemia. In this study, no major hypoglycemic events were reported by the patients. However, 39 
TABLE 2: Mean daily dose of oral hypoglycemic agents and insulin at baseline.

\begin{tabular}{|c|c|c|c|c|c|}
\hline $\begin{array}{l}\begin{array}{l}\text { Drug class } \\
\text { (number of } \\
\text { patients) }\end{array} \\
\end{array}$ & $\begin{array}{l}\text { Metformin } \\
(n=119)\end{array}$ & $\begin{array}{l}\text { Glipizide }^{\mathrm{b}} \\
(n=70)\end{array}$ & $\begin{array}{l}\text { Sitagliptin }^{\mathrm{c}} \\
\quad(n=10)\end{array}$ & $\begin{array}{l}\text { Mealtime insulin } \\
\qquad(n=62)\end{array}$ & $\begin{array}{l}\text { Basal insulin } \\
\quad(n=92)\end{array}$ \\
\hline $\begin{array}{l}\text { Mean daily dose } \\
\text { (mg/unit) }\end{array}$ & $1795.0 \pm 698.4 \mathrm{mg}$ & $15.9 \pm 9.4 \mathrm{mg}$ & $65.0 \pm 24.2 \mathrm{mg}$ & $30.7 \pm 24.1$ units & $38.1 \pm 27.5$ units \\
\hline
\end{tabular}

Values are represented as means $\pm \mathrm{SD}$.

${ }^{\text {a }}$ Other oral hypoglycemic agents not included in the table were acarbose $(n=3 ; 100 \pm 0 \mathrm{mg}$ daily), pioglitazone $(n=2 ; 22.5 \pm 10.6 \mathrm{mg}$ daily), and repaglinide $(n=1 ; 1 \pm 0 \mathrm{mg}$ daily).

${ }^{\mathrm{b}}$ Glipizide-equivalent dose for sulfonylurea was calculated for tolbutamide, gliclazide, and glyburide [19, 20].

${ }^{c}$ One participant was given s-linagliptin (5 mg daily).

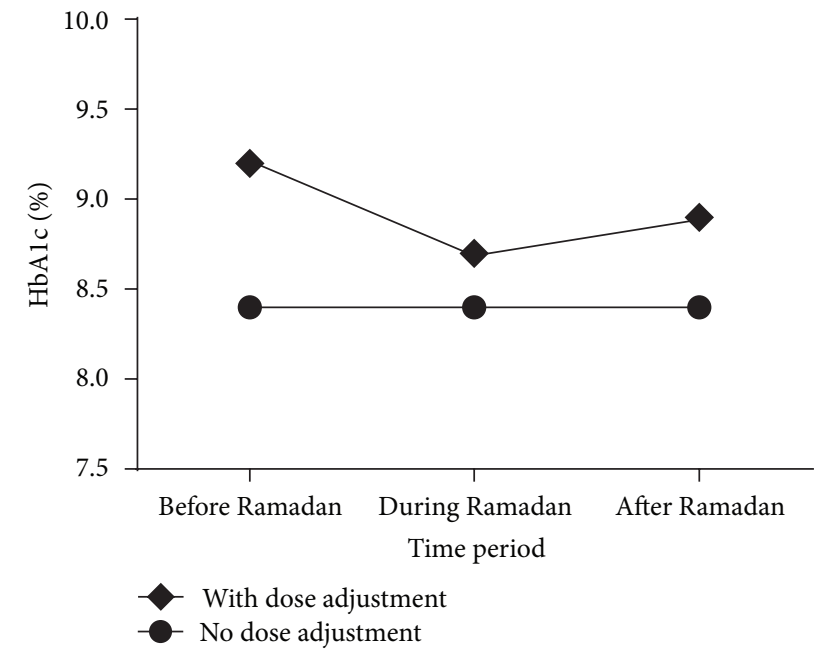

FIGURE 2: Trends of change in mean HbAlc in relation to adjustment of the dose of antidiabetic agents.

(25.5\%) patients reported having experienced minor hypoglycemia during Ramadan and of which 17 (43.6\%) were on combination regimen of $\mathrm{OHA}$ and insulin, 14 (35.9\%) were on OHA alone, and 8 (20.5\%) were on insulin alone. Commonly reported hypoglycemic symptoms included dizziness, tremors, increased sweating, extreme hunger, increased heart rate or palpitation, and increased frequency of headaches, nausea, confusion, and mood changes.

\section{Discussions}

This was the first prospective study to observe the changes in glycemia before, during, and after Ramadan fasting and also provided a comprehensive understanding on the effects of lifestyle modification and dose adjustment on glycemia during Ramadan fasting.

In this study, a significant reduction of $0.3 \%$ in mean HbAlc was observed during Ramadan fasting. Although an improvement in glycemia was found, a $25.5 \%$ rate of minor hypoglycemia occurred in these patients. While any form of hypoglycemic event is undesirable in the management of diabetes, this rate is nevertheless lower than or comparable with other studies conducted in nonfasting patients with type 2 diabetes. A cross-sectional study by Miller et al. [21] reported hypoglycemia rates of $12 \%$ for patients on diet alone, $16 \%$ for patients on OHA, and 30\% for patients on insulin.

Some studies have shown that people who received adjustments to antidiabetic drug doses during Ramadan achieved better glucose control $[22,23]$. A study reported by Mafauzy [22] showed that those with adjustments to their dose of OHA experienced a larger reduction in their level of fructosamine $(-21.9 \pm 4.8 \mu \mathrm{mol} / \mathrm{L})$ than those with no adjustment to their OHA dose $(-6.7 \pm 5.6 \mu \mathrm{mol} / \mathrm{L})$ during Ramadan $(P=0.01)$. In another study by Hui et al. [23], patients who were switched to faster-acting insulin had an improvement of $0.48 \%$ in $\mathrm{HbAlc}(P=0.0001)$ while those who were maintained on the same insulin regimen had an improvement of only $0.28 \%$ in $\operatorname{HbAlc}(P=0.007)$ during Ramadan. Similarly, this study also showed a larger reduction in HbAlc among those with adjustments to their dose of antidiabetic agents. Indeed, the attempt to mimic the physiological secretion of insulin by adjusting the dose during Ramadan may have contributed to the improvement in glycemia.

In our study, diet and physical activity were not found to be related to a reduction in HbAlc during Ramadan. This lack of an association could be explained by examining the pattern of dietary intake and the level of physical activity in our study population. During Ramadan, the majority of patients reported that their dietary intakes were reduced but this surprisingly did not contribute to a reduction in glycemia. One possible reason could be that these patients had perceived a reduction in their dietary intakes due to the reduction in meal frequency but that their daily caloric intakes may have remained the same throughout Ramadan. A study conducted by Haouari-Oukerro et al. [24] showed that overall caloric consumption remained unchanged even though the number of meals was reduced to twice daily during the fasting month. In addition, most of our patients did not report any change in their physical activities during Ramadan; hence, the effect of physical activity on glycemia may be very small in this population. Furthermore, our findings were also observed in several studies in which glycemic control was not associated with physical activity $[25,26]$.

This study had several limitations. First, it relied on patient self-reporting for certain information such as dietary pattern, physical activity, the incidence of hypoglycemia, and the management of diabetes. Recall bias may have affected the quality of our data but, whenever possible, we also compared 
the patients' responses with objective data found in patient case notes and the clinical database. Second, we had to exclude $39 \%$ of the patients recruited due to our stringent criteria of accepting only questionnaires with a $100 \%$ response rate. However, based on the drop-out rate of $32-44.2 \%$ of similar studies [27-29], our response rate appears to be reasonable.

Future studies should compare various types of OHA in relation to their risks for hypoglycemic events during Ramadan fasting. This will allow patients and clinicians to closely monitor antidiabetic agents that may be more likely to contribute to hypoglycemic symptoms during Ramadan. In addition, the quality of pre-Ramadan structured education on diet, physical activity, and dose adjustment of medication should also be evaluated to ensure effective and safe diabetes management and positive outcomes.

\section{Conclusions}

Ramadan fasting was observed to improve glycemic control among our patient population with minimal hypoglycemic events. The improvement in HbAlc was more notable in patients whose medications were adjusted in an attempt to mimic the physiological secretion of insulin throughout the fasting period. During Ramadan, clinicians should individualize the dosing of antidiabetic agents especially in patients who intend to fast.

\section{Conflict of Interests}

The authors have no conflict of interests to declare.

\section{Acknowledgments}

There is no funding or acknowledgement to declare. Parts of this study were published in a form of abstract in Diabetes, volume 62 (supplement) pp. A315, July 2013.

\section{References}

[1] M. I. Bashir, M. F. Pathan, S. A. Raza et al., "Role of oral hypoglycemic agents in the management of type 2 diabetes mellitus during Ramadan," Indian Journal of Endocrinology and Metabolism, vol. 16, no. 4, pp. 503-507, 2012.

[2] I. Salti, E. Bénard, B. Detournay et al., "A population-based study of diabetes and its characteristics during the fasting month of ramadan in 13 countries: results of the epidemiology of diabetes and ramadan 1422/2001 (EPIDIAR) study," Diabetes Care, vol. 27, no. 10, pp. 2306-2311, 2004.

[3] K. M. S. Mansi, "Study the effects of Ramadan fasting on the serum glucose and lipid profile among healthy Jordanian students," American Journal of Applied Sciences, vol. 4, no. 8, pp. 565-569, 2007.

[4] M. M'Guil, M. A. Ragala, L. El Guessabi et al., "Is Ramadan fasting safe in type 2 diabetic patients in view of the lack of significant effect of fasting on clinical and biochemical parameters, blood pressure, and glycemic control?" Clinical and Experimental Hypertension, vol. 30, no. 5, pp. 339-357, 2008.
[5] B. Benaji, N. Mounib, R. Roky et al., "Diabetes and Ramadan: review of the literature," Diabetes Research and Clinical Practice, vol. 73, no. 2, pp. 117-125, 2006.

[6] S. K. Vasan, R. Karol, N. V. Mahendri, N. Arulappan, J. J. Jacob, and N. Thomas, "A prospective assessment of dietary patterns in Muslim subjects with type 2 diabetes who undertake fasting during Ramadan," Indian Journal of Endocrinology and Metabolism, vol. 16, no. 4, pp. 552-557, 2012.

[7] B. M. Khaled and S. Belbraouet, "Effect of Ramadan fasting on anthropometric parameters and food consumption in 276 type 2 diabetic obese women," International Journal of Diabetes in Developing Countries, vol. 29, no. 2, pp. 62-68, 2009.

[8] N. R. Pinelli and L. A. Jaber, "Practices of Arab American patients with type 2 diabetes mellitus during Ramadan," Journal of Pharmacy Practice, vol. 24, no. 2, pp. 211-215, 2011.

[9] V. Ziaee, M. Razaei, Z. Ahmadinejad et al., "The changes of metabolic profile and weight during Ramadan fasting," Singapore Medical Journal, vol. 47, no. 5, pp. 409-414, 2006.

[10] M. Al-Arouj, S. Assaad-Khalil, J. Buse et al., "Recommendations for management of diabetes during Ramadan: update 2010," Diabetes Care, vol. 33, no. 8, pp. 1895-1902, 2010.

[11] P. E. Cryer, S. N. Davis, and H. Shamoon, "Hypoglycemia in diabetes," Diabetes Care, vol. 26, no. 6, pp. 1902-1912, 2003.

[12] M. A. Almaatouq, "Pharmacological approaches to the management of type 2 diabetes in fasting adults during Ramadan," Diabetes, Metabolic Syndrome and Obesity: Targets and Therapy, vol. 5, pp. 109-119, 2012.

[13] S. H. Bonakdaran and M. Khajeh-Dalouie, "The effects of fasting during ramadan on glycemic excursions detected by continuous glucose monitoring system (CGMS) in patients with type 2 diabetes," Medical Journal of Malaysia, vol. 66, no. 5, pp. 447-450, 2011.

[14] Singapore Census of Population, "Census of population 2010 statistical release 1: education, language and religion," Department of Statistics, Ministry of Trade and Industry, Singapore, 2010, http://www.singstat.gov.sg/publications/publications_and_papers/cop2010/census10_stat_releasel.html.

[15] "Hari Raya Aidilfitri," Singapore Tourism, 2014, http://www .yoursingapore.com/content/traveller/en/browse/whats-on/festivals-and-events/hari-raya-aidilfitri.html.

[16] A. Norouzy, S. M. R. Mohajeri, S. Shakeri et al., "Effect of Ramadan fasting on glycemic control in patients with type 2 diabetes," Journal of Endocrinological Investigation, vol. 35, no. 8, pp. 766-771, 2012.

[17] F. A. Khatib and Y. A. Shafagoj, "Metabolic alterations as a result of Ramadan fasting in non-insulin-dependent diabetes mellitus patients in relation to food intake," Saudi Medical Journal, vol. 25, no. 12, pp. 1858-1863, 2004.

[18] J. Y.-C. Lee, K. Tsou, J. Lim, F. Koh, S. Ong, and S. Wong, "Symptom-based Insulin adjustment for Glucose Normalization' (SIGN) algorithm: a pilot study," Diabetes Technology \& Therapeutics, vol. 14, no. 12, pp. 1145-1148, 2012.

[19] J. T. Dipiro, R. L. Talbert, G. C. Yee, G. R. Matzke, B. G. Wells, and L. M. Posey, Pharmacotherapy: A Pathophysiologic Approach, McGraw-Hill, New York, NY, USA, 2008.

[20] British National Formulary, BMJ Group and Pharmaceutical Press, 2014.

[21] C. D. Miller, L. S. Phillips, D. C. Ziemer, D. L. Gallina, C. B. Cook, and I. M. El-Kebbi, "Hypoglycemia in patients with type 2 diabetes mellitus," Archives of Internal Medicine, vol. 161, no. 13, pp. 1653-1659, 2001. 
[22] M. Mafauzy, "Repaglinide versus glibenclamide treatment of type 2 diabetes during Ramadan fasting," Diabetes Research and Clinical Practice, vol. 58, no. 1, pp. 45-53, 2002.

[23] E. Hui, V. Bravis, S. Salih, M. Hassanein, and D. Devendra, "Comparison of Humalog Mix 50 with human insulin Mix 30 in type 2 diabetes patients during Ramadan," International Journal of Clinical Practice, vol. 64, no. 8, pp. 1095-1099, 2010.

[24] F. Haouari-Oukerro, M. Ben-Attia, N. Kaâbachi, and M. Haouari, "Ramadan fasting influences on food intake consumption, sleep schedule, body weight and some plasma parameters in healthy fasting volunteers," African Journal of Biotechnology, vol. 12, no. 21, pp. 3327-3332, 2013.

[25] M. A. Abdulrahman, A. J. Manssor, and M. M. Marbut, "The effect of Ramadan fasting \& moderate exercise on body weight, serum glucose \& lipid profile in healthy fasting subjects," Medical Journal of Tikrit, vol. 2, no. 122, pp. 26-30, 2006.

[26] N. Khan, M. H. Khan, M. Zaman Shaikh, M. R. Khanani, and A. Rasheed, "Effects of Ramadan fasting and physical activity on glucose levels and serum lipid profile among type 2 diabetic patients," Pakistan Journal of Medical Sciences, vol. 28, no. 1, pp. 91-96, 2012.

[27] V. Ruelas, G. M. Roybal, Y. Lu, D. Goldman, and A. Peters, "Clinical and behavioral correlates of achieving and maintaining glycemic targets in an underserved population with type 2 diabetes," Diabetes Care, vol. 32, no. 1, pp. 54-56, 2009.

[28] K. M. P. van Bastelaar, F. Pouwer, P. Cuijpers, H. Riper, and F. J. Snoek, "Web-based depression treatment for type 1 and type 2 diabetic patients: a randomized, controlled trial," Diabetes Care, vol. 34, no. 2, pp. 320-325, 2011.

[29] A. K. Diehl, N. J. Sugarek, and R. L. Bauer, "Medication compliance in non-insulin-dependent diabetes: a randomized comparison of chlorpropamide and insulin," Diabetes Care, vol. 8, no. 3, pp. 219-223, 1985. 


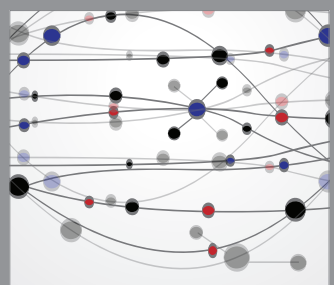

The Scientific World Journal
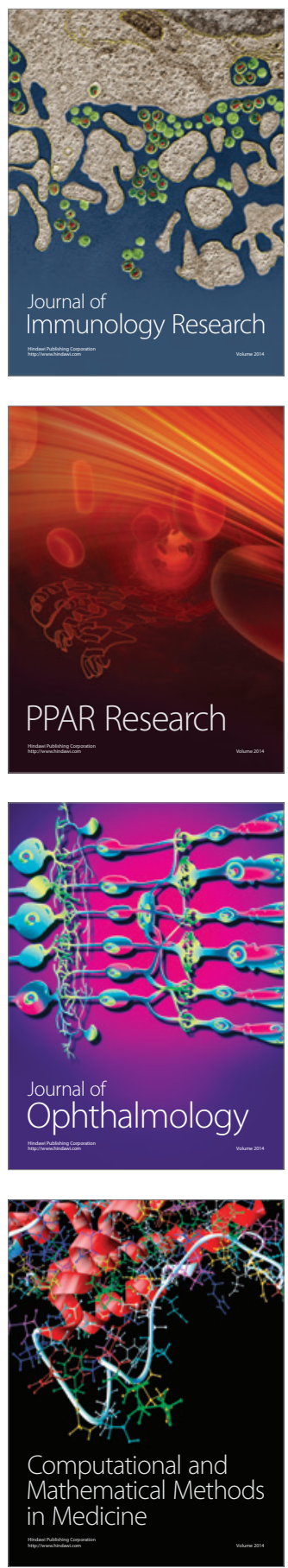

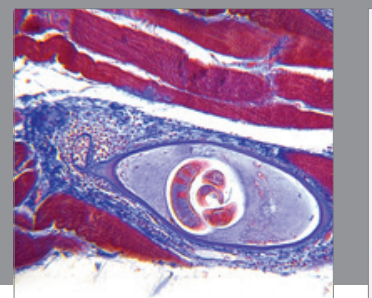

Gastroenterology

Research and Practice
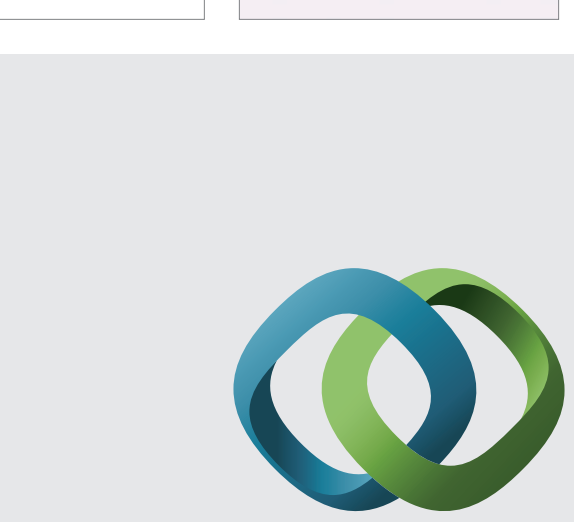

\section{Hindawi}

Submit your manuscripts at

http://www.hindawi.com
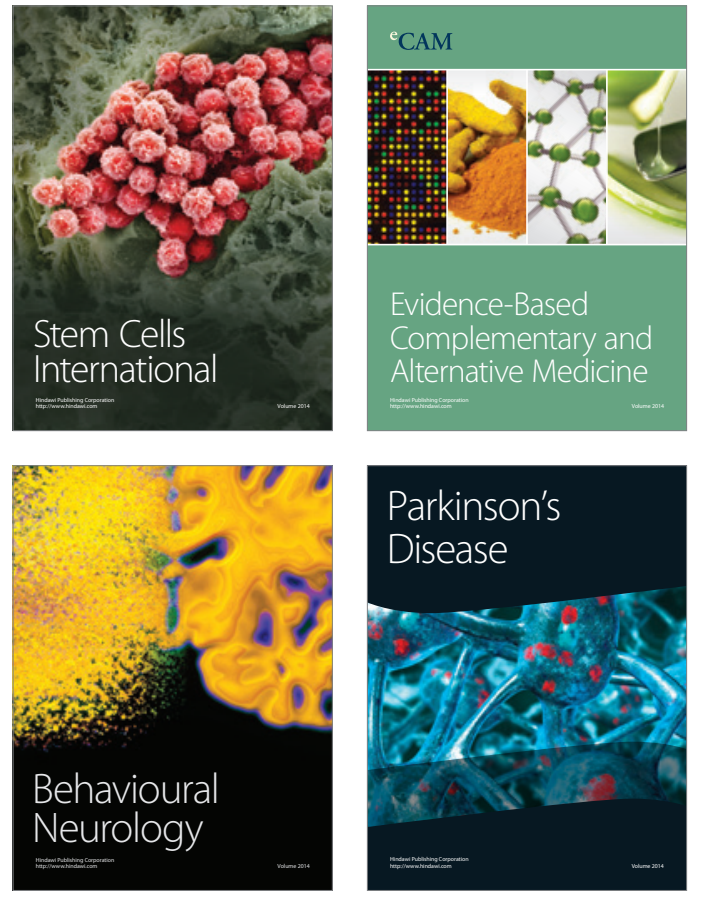
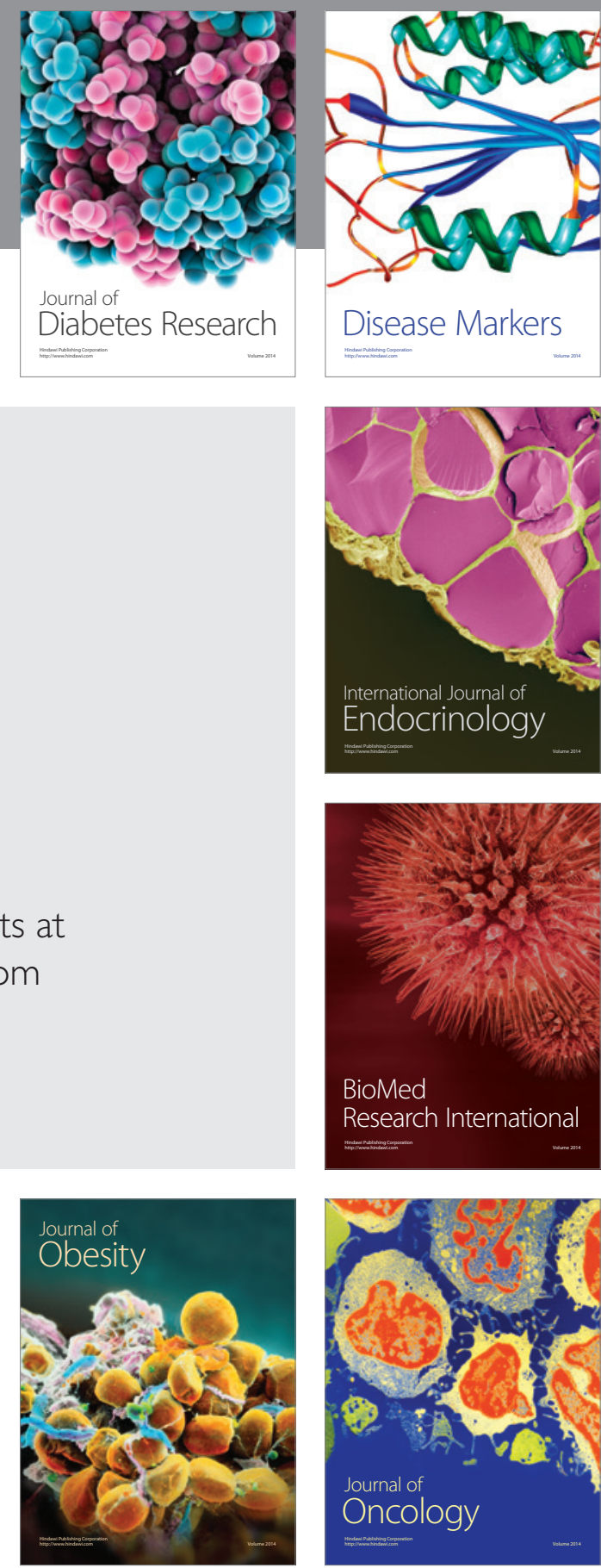

Disease Markers
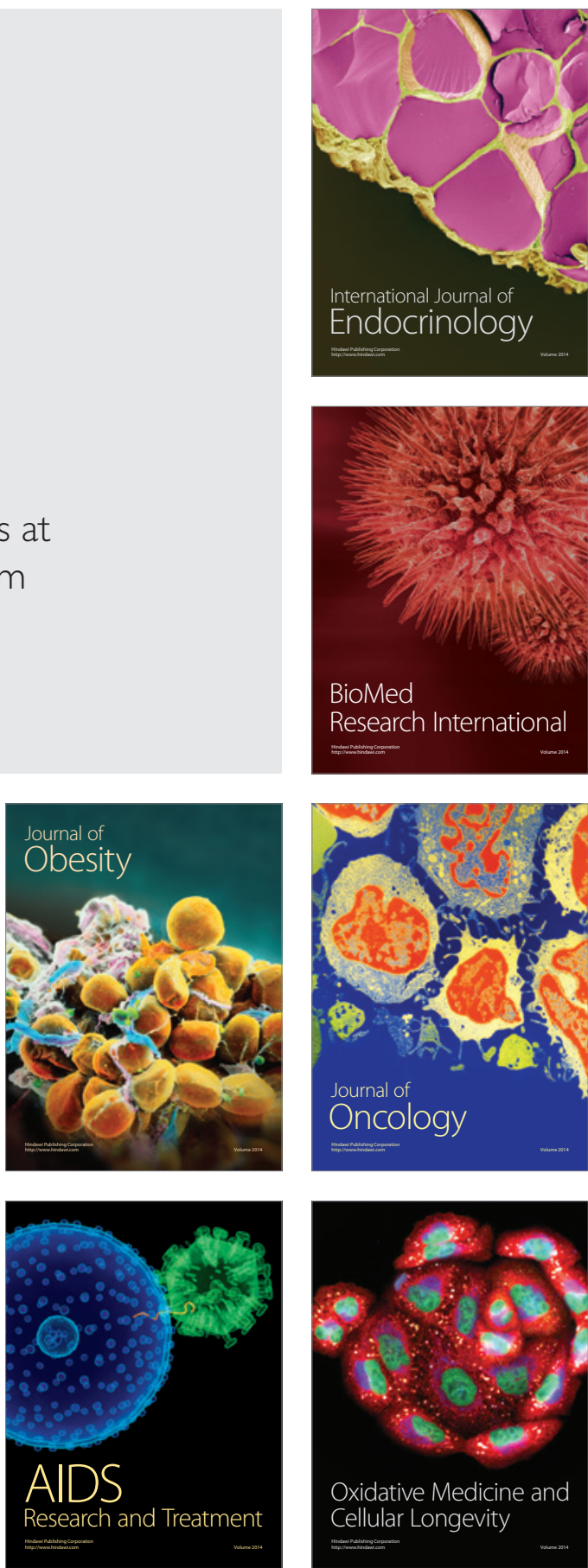